\title{
Forces determination on the steering wheel of an automobile vehicle
}

\author{
[Gómez, A. M., Olmeda, E., Sanz, S., Garrosa, M., Sáez, R., Díaz, V.]
}

\begin{abstract}
Facing the problem of experimental measurement of a torque that a motor vehicle driver applies on the steering wheel, it is required to study the devices prepared for this purpose. In the current market we can already find some tools with this aim, such as the dynamometric steering wheel. The exact measurement of the strength obtained in the steering wheel when making it turn is of great importance, due to the fact that all motor vehicles in use have to comply with the Directive 70/311/EEC, in which it is specified the maximum value of the force pressed on the steering wheel of any vehicle when performing a change of direction. As a consequence, in spite of the existence of available devices, it is advisable to follow the research on different measurement methods, since opting for the dynamometric steering wheel can raise costs and has an apparent lack of precision.
\end{abstract}

Therefore, in this paper a new method of measuring torque in a motor vehicle is implemented, so that the use of the already existing dynamometric steering wheel is not necessary.

It is concluded and demonstrated that the device described here has higher accuracy than the dynamometric steering wheel when an automobile vehicle is tested in order to comply with the current European regulations.

Keywords - extensometry, sensor, dynamometric steering wheel, lateral dynamics.

\section{Introduction}

The requirements of the vehicles about comfort, performance and safety are increasingly more, extending the technical requirements contained in numerous national and international legislations.

About the steering system of a vehicle, the fundamental objectives of its operations are to allow the control of the vehicle in order to choose the trajectory to follow (analyzed with the lateral dynamics) and to provide a steady movement when it is submitted to variations of different origins [1], [2].

Besides, a correct interaction human-vehicle-means is fundamental to get a safe driving. Due to the reversibility of the steering system, the driver "feels" the road through small oscillations on the steering wheel, so the driver turns it and obtains a good directional response. In this aspect the torque that the driver has to apply is very relevant.

Gómez, A. M., Olmeda, E., Sanz, S., Garrosa, M., Sáez, R., Díaz, V. Instituto de Seguridad de Vehículos Automóviles (ISVA), Universidad Carlos III de Madrid

Spain
Facing the problem of experimental measurement of a torque that a motor vehicle driver applies on the steering wheel, it is required to study the devices prepared for this purpose. In the current market we can already find some tools with this aim, such as the dynamometric steering wheel.

The exact measurement of the strength obtained in the steering wheel when making it turn is of great importance, due to the fact that all vehicles in use have to comply the Directive 70/311/EEC [3], in which it is specified the maximum value of the force pressed on the steering wheel of any vehicle when performing a change of direction. Moreover, an excessive stress on the wheel can lead to fatigue in the driver, putting road safety at risk. Furthermore, the economic cost of the dynamometric steering wheel, compounded with a certain lack of precision in its measure (which will be justified later), make it convenient to continue investigating different methods of measurement.

\section{Objetives}

In this paper is presented a new device for measuring the torque that a driver applies on the steering wheel of his automobile vehicle, either private or industrial type. This device has more precision than the current dynamometric steering wheel and is visibly much more economical, since its design is simpler, it requires less maintenance and its installation is simple and universal, enabling its quick installation in any type of vehicle. This device is based on an extensometric type sensor and, unlike the dynamometric steering wheel that only measures the torque applied on the steering shaft, it measures directly the net force of the driver on the steering wheel.

\section{Methodology}

\section{A. Applicable regulations}

The Directive 70/311/EEC, relative to the approximation of the laws of the Member States concerning the steering equipment for motor vehicles and their trailers, dictates the specific requirements of compulsory compliance and the corresponding tests, whose verification gives to those vehicles the CE marking.

The first modification was published in 1992, Directive $92 / 62 / E E C$. It was written in order to adapt it to the improvements on road safety acquired through measurements based on practice experience, technical advances and studies of the United Nations Economic Commission for Europe. Some of these improvements concern the following themes:

The reduction of the force on the steering wheel. 
The introduction of a new turn test at a higher speed for the motor vehicles.

The second and the last adaptation published to date is the Directive 1999/7/EC. It refers to Directive 70/156/EEC, relative to the homologation for motor vehicles and their trailers, applicable to the Directive already studied. Besides, the organization of the document is restructured, making it easier to understand.

The Directive 70/311/EEC describes a series of tests that are of compulsory compliance to grant European homologation. In one of the tests, the vehicle has to move initially in a straight line, and then it has to turn with the specified radius with a speed of $10 \mathrm{~km} / \mathrm{h}$. The force applied on the steering wheel has to be measured by using a measurement device when the steering wheel provides a trajectory whose turn radius is as required. The forces applied during less than 0.2 seconds will not be taken in consideration.

\section{B. Problems of the dynamometric steering wheel}

The most direct and simple method for performing the necessary measurements of force is, at present, the dynamometric steering wheel (Figure 1).

The wheel is affixed parallel and adjusted to the steering wheel of the vehicle. In order to measure the angle of rotation of the wheel, an extensible metal rod is tied to the windshield. In the Figure 1 can be observed the discomfort that can be caused to the driver while driving with this mechanical contraption. Also the seat height adjustment does not allow an ergonomic driving.

This device provides direct measurement of the torque applied on the wheel, the spindle speed and the angle of rotation of the wheel. As stated earlier, the adaptation of the dynamometric steering wheel in the vehicle is made on the vehicle's steering wheel. The support of the dynamometric steering wheel has an adapter that allows adjustment on steering wheels of different diameters, though its size can affect to the driving [4]

When the steering wheel is operated manually, due to the turn of the wrist, the force applied by the driver $(\mathrm{F})$ over the wheel is divided into a tangential force $\left(F_{r}\right)$ and a normal force $\left(\mathrm{F}_{\mathrm{N}}\right)$. Of these two components, the one that generates torque on the steering wheel is the tangential force, so that the device is only able to measure this force, taking no account of the value of the normal force applied (Figure 2). This error depends directly on the physiological characteristics of each driver. For this reason, the dynamometric steering wheel provides inaccurate results, since it shows a value of the torque below the net torque that is really applied on the steering wheel by the driver.

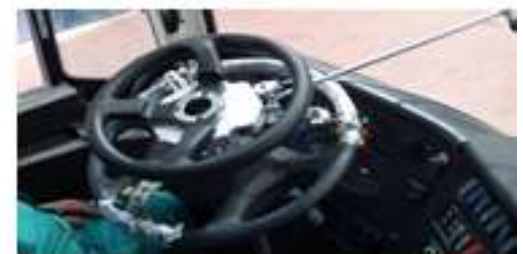

Figure 1. Dynamometric steering wheel

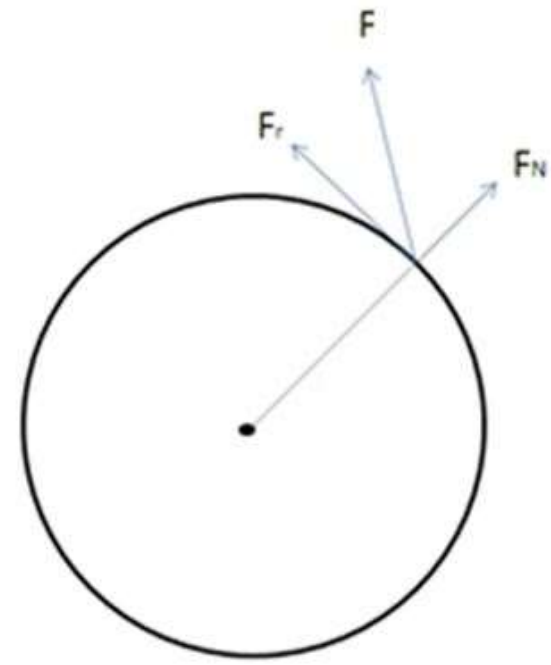

Figure 2. Forces generated on the dynamometric steering wheel

The problem of using this method to calculate the forces to check the compliance with the Directive 70/311/EEC is high, as its results are lower values of force and it may give as valid a test of homologation of a vehicle that in truth does not comply and should not be able to circulate. Besides, the cost of this device is quite high.

\section{Device design}

In order to solve the problem caused by the dynamometer wheel, a new method is presented for measuring the torque exerted on the steering wheel, being capable of measuring the total force applied to the device and ensuring thus full compliance with the Directive 70/311/EEC.

The force measuring device is developed allowing its adaptation to any steering wheel using a universal knob, previously used to facilitate driving for disabled people. During operation, the device turns on itself, being the torque exerted by the driver on its axis null. Therefore the normal force on the wheel and perpendicular to former rotation axis is cancelled. Accordingly, the torque generated by the rotating movement on itself is zero (Figure 3). Thus the undesired component of the normal force generated in the dynamometer wheel is eliminated, and consequently the net effort applied on it can be measured exactly. By means of a strain gauge placed on the device, strains that occur on the shaft, namely the axis of rotation, are determined. The forces are then measured, being necessary to check if the applied force complies with the requirements of Directive test.

The design of this new force measuring device allows greater accuracy on the values of force applied to the steering wheel, reducing the cost relative to the dynamometer wheel significantly and providing better ergonomics in the test procedures. 
Proc. of the Third Intl. Conf. on Advances in Mechanical and Automation Engineering - MAE 2015.

Copyright (C) Institute of Research Engineers and Doctors, USA .All rights reserved.

ISBN: 978-1-63248-080-4 doi: 10.15224/ 978-1-63248-080-4-77

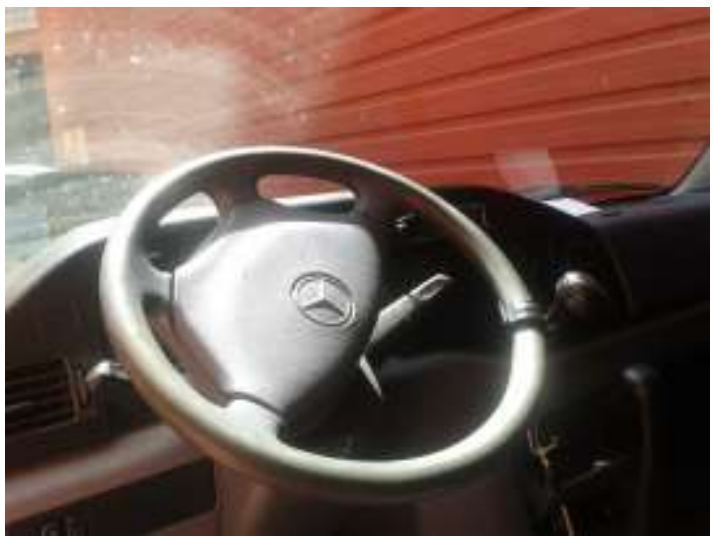

Figure 3. Measuring device of force

\section{Calculation of limit deformations (FEM)}

For the verification of compliance with the requirements of Directive 70/311/EEC in terms of force applied to the wheel, theoretical parameters that define these limits are calculated in order to be compared with experimental acquired data through the device designed.

The theoretical limit deformation that occurs on the wheel's stem when the maximum forces allowed by the regulations are applied is obtained by means of the Finite Element Method. The table refers to the test number 3 of the Directive, where different forces are specified by category of tested vehicle and the status of its steering mechanism. Therefore, the theoretical calculation for each of these forces applied on the measuring device $(150 \mathrm{~N}, 200 \mathrm{~N}, 250 \mathrm{~N}, 300$ $\mathrm{N}, 400 \mathrm{~N}$ and $450 \mathrm{~N}$ ) is performed.

Thus, theoretical data are compared with experimental data (provided directly), which allows a perception of how the designed device operates.

In order to know the range of deformation where the device is working, a first approximation of the limit deformation is performed by using the finite element software Abaqus / CAE. To model it, the stem device is simulated in the software as if it were a cantilever beam closed at one end.

The fixed end of the beam is the zone in contact with the wheel, while the opposite end is the zone where the force is applied.

For the simulation of the stem, it has been used a bolt with a head of $15 \mathrm{~mm}$ of diameter and a stem of $45 \mathrm{~mm}$ whose metric is M10 of $25 \mathrm{~mm}$ of length with a cut of 20 mm of length.

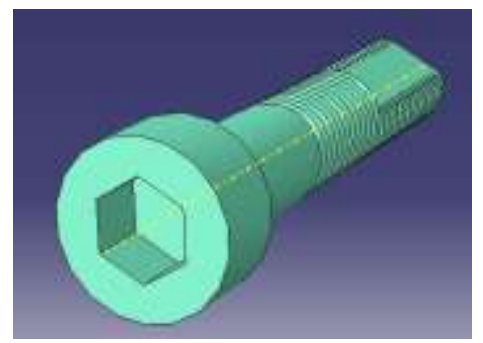

Figure 4. Screw geometry made with Abaqus software

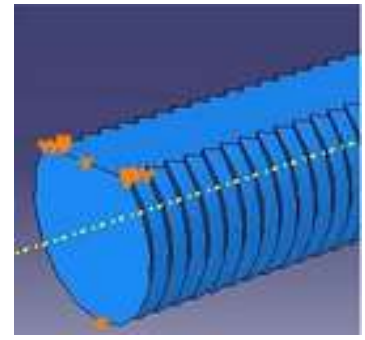

Figure 5. Boundary conditions

To implement this device properly, the stem is cut longitudinally with two purposes: first, shaping the stem in order to achieve a proper deflection; and secondly, a strain gauge of small dimensions can be placed. Once the stem is drawn in the software (Figure 4), the material (steel) and mechanical properties are introduced into the model, being the Young's modulus $\mathrm{E}=210 \mathrm{GPa}$ and Poisson's ratio $v=$ 0.3. The boundary conditions (Figure 5) are introduced, the piece is covered with a mesh pattern and the test is carried out.

In Table 1 maximum strain data obtained by this method are shown.

Plotting the data in Figure 6, the theoretical force (F) deformation $(\varepsilon)$ curve is obtained, the function that relates these two variables can be obtained from the curve:

$$
\mathrm{F}=2207250.8808 \varepsilon-0.0105
$$

\section{E. Instrumentation}

For the construction of the device, a universal steering wheel knob that turns on itself is selected, and the stem is extracted from the inside. The bolt is shaped in order to appreciate the strain measured by the strain gauge. In addition, a flat, smooth and clean surface must be obtained. The material shaping cannot involve high strains or cracks in any way. This is checked with FEM.

The strain gauge which is going to be on the stem is selected [5]. The strain gauge FLA 1-11, whose features are shown in the table 2, is located at the bolt, and the ends of the pins of the gauge are welded to a network cable in order to connect it with the data acquisition system used in the experiment (Figure 7). Finally, it is covered with a twocomponent glue in order to avoid the metal-to-metal contact.

Table 1. Maximum strains allowed under applied stress

\begin{tabular}{|cc|}
\hline APPLIED & MAXUMUM \\
FORCE $(\mathrm{N})$ & STRAIN $(\mathrm{m} / \mathrm{m})$ \\
\hline $\mathbf{1 5 0}$ & $6.79610^{-5}$ \\
$\mathbf{2 0 0}$ & $9.06110^{-5}$ \\
$\mathbf{2 5 0}$ & $1.13310^{-4}$ \\
$\mathbf{3 0 0}$ & $1.35910^{-4}$ \\
$\mathbf{4 0 0}$ & $1.81210^{-4}$ \\
$\mathbf{4 5 0}$ & $2.03910^{-4}$ \\
\hline
\end{tabular}




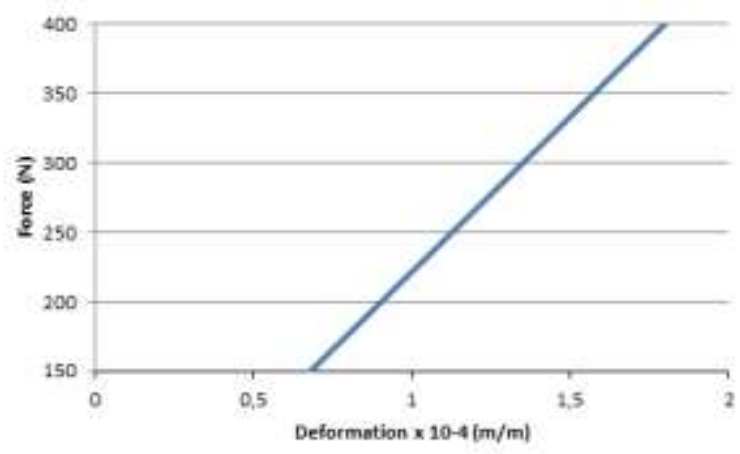

Figure 6. Straight Force $(\mathrm{N})$ - Theoretical deformation $(\mathrm{m} / \mathrm{m})$

In order to obtain the strain data, a Vishay MicroMeasurements System 7000 data acquisition system is used, with the Strain Smart software, that allow to obtain strain measurements over time. After calibrating the device and determining the calibration function that relates the force with the strain, the force applied at the device is calculated and it can be checked if, for a certain turning angle of the wheel, the force is inside the criteria of the Directive and if it complies with it.

\section{Conclusions}

This paper has analyzed the need to take measurements of the force applied on the steering wheel periphery when the vehicle turns. It has studied the possibility of using a force sensor on the steering wheel periphery instead of the usual dynamometric steering wheel. For this purpose, a theoretical analysis of the behavior of this device has been done, using an extensometry and FEM.

The new device provides a more exact and realistic measurement than the dynamometric steering wheel. The reason for the dynamometric steering wheel's inexactitude is that a force is created by the hand movement; this force can be divided into two forces, normal and tangential, where the last one generates a torque and is the only measured force, which amounts to less than full force. The new design allows rotation on itself, and in its case only one force exists, the tangential one. This design has aptly removed the problem of reliability with the test of 70/331/EEC, because the full force is measured and the obtained results are valid.

It is also important to indicate that the extensometric device is cheaper than the dynamometric steering wheel.

This device is under patent prior to its commercial exploitation.

Table 2. Features of the FLA-1-11 strain gauge

\begin{tabular}{|cc|}
\hline TYPE & FLA-1-11 \\
\hline Lot & A510211 \\
Gage factor $(\mathbf{K})(\boldsymbol{\%})$ & $2.14 \pm 1$ \\
Length $(\mathbf{m m})$ & 1 \\
Resistance $(\boldsymbol{\Omega})$ & $120 \pm 0.3$ \\
\hline
\end{tabular}

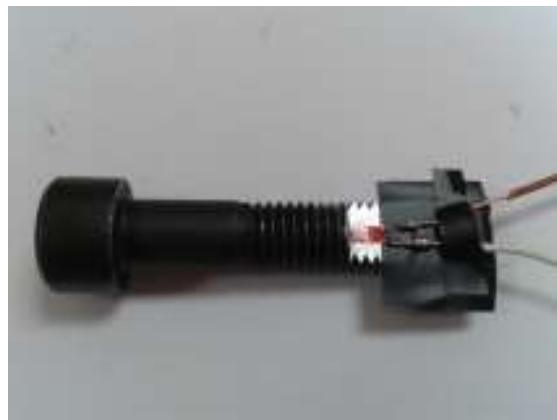

Figure 7. Strain gauge located at the stem

\section{v. Future works}

There are many studies on this paper that have not yet been developed and can be proposed as future works:

- Comparison of the above mentioned theoretical method with an experimental method based on measuring device calibration to obtain the calibration curve and the function.

- Comparison of the experimental results while using a dynamometric steering wheel in the vehicle to those using the designed device.

- Calculation of the associated measurement uncertainty to the designed measuring device.

\section{References}

[1] F. Aparicio, C. Vera y V. Díaz, Teoría de los vehículos de los vehículos automóviles, ETS Ingenieros Industriales, España, 1995.

[2] V. Díaz et al., Automóviles y ferrocarriles, UNED, España, 2012.

[3] Directive 70/311/EEC of 8 June 1970 on the approximation of the laws of the Member States relating to the steering equipment for motor vehicles and their trailers.

[4] Dynamometric steering wheel Manual, Kistler.

[5] Strain gauges, Tokyo Sokki Kenkyujo Co., Ltd.

About Author (s)

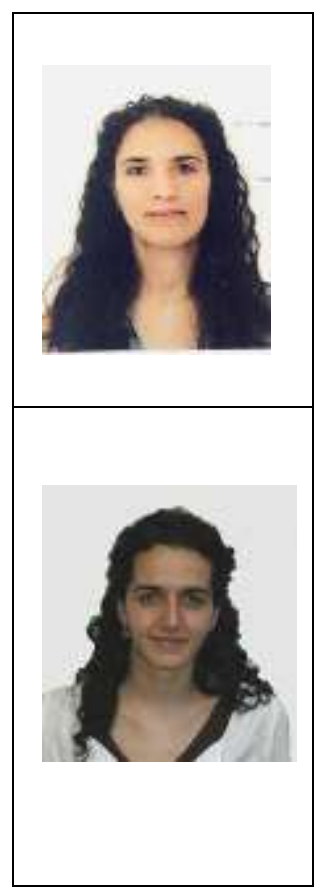

Ana María Gómez, member of ISVA and Mecatran research group, received her Master's Degree in Industrial Engineering from Madrid Polytechnic University in 2002. She was working 10 years in Energy Engineering Companies us a project manager. She is currently a research assistant and Professor in Department of Mechanical Engineering at UC3M. Her research area includes control of vehicle lateral dynamics, vehicles and bus dynamics.

Ester Olmeda member of ISVA and Mecatran research group, received her Master's Degree in Mechanical Engineering from the Polytechnic University of Madrid in 2003 (main subject of Machines). After two years working in the Mechanical and Manufacturing Engineering Department at the Polytechnic University, she joined the Mechanical Engineering Department of the University Carlos III of Madrid. She has been working there as Research and Professor since then. In this University she obtained her $\mathrm{PhD}$ in Mechanical Engineering in 2008. Her research interests include machinery safety, tribology, vehicles and bus dynamics. 
Proc. of the Third Intl. Conf. on Advances in Mechanical and Automation Engineering - MAE 2015.

Copyright (C) Institute of Research Engineers and Doctors, USA .All rights reserved.

ISBN: 978-1-63248-080-4 doi: 10.15224/ 978-1-63248-080-4-77

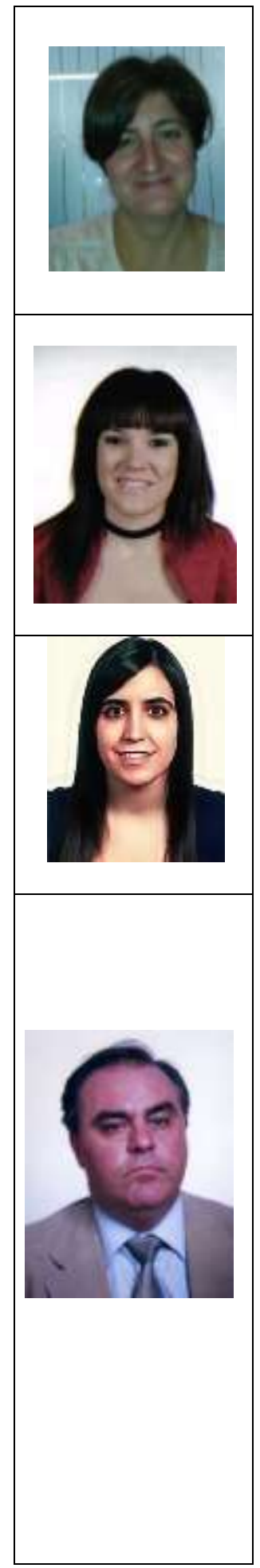

Susana Sanz, member of ISVA and Mecatran research group, received her Degree in Mechanical Engineering and Master's Degree in Mechanical Engineering and transportation from Carlos III University of Madrid in 2009 and 2012, respectively. She is currently a research assistant and Professor of The Mechanical Engineering Department at UC3M. Her research area includes vehicles and stability control form automobile vehicles.

María Garrosa, member of ISVA and Mecatran research group, received her Degree in Mechanical Engineering and Master's Degree in Mechanical Engineering and transportation from Carlos III University of Madrid in 2012 and 2014, respectively. She is currently a research assistant and Professor of the Mechanical Engineering Department at UC3M. Her research area includes vehicles, machinery safety and stability control form automobile vehicles.

Ruth Sáez, member of ISVA and Mecatran research group, received her Degree in Industrial Engineering from Carlos III University of Madrid in 2015. She is currently a research assistant and Professor of the Mechanical Engineering Department at UC3M. Her research area includes control of vehicle lateral dynamics.

Vicente Díaz is Full Professor of the Mechanical Engineering Department of Carlos III University and leader of research group Mecatran. His area of expertise at UC3M is in the field of transports, vehicle dynamics engineering, end-of-life recycling and motor vehicle inspection. He has a great number of publications and papers indexed in JCR relative to vehicle dynamic modelling (including heavy vehicle), vehicle lateral control and tyre modelling. He has been leader of projects which have been developed for the automobile industry as well as leader in tyre research competitive government projects. In addition, he has supervised several $\mathrm{PhD}$ Thesis on bus structure dynamics, tyre modelling and Electronic Stability Control for automobile vehicles. 